\title{
Mother Goose in the NICU
}

\section{Support for the Neediest Infants and Their Families}

BETSY DIAMANTCCOHEN, SUSAN SONNENSCHEIN, DAWN SACKS, SUMMMER ROSSWOG, AND BRENDA HUSSEY-GARDNER

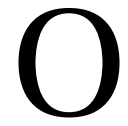

$\mathrm{f}$ the 76,510 babies born during an average week in the United States, 7,361—or about 10 percent—are born prematurely. ${ }^{1}$ Preterm babies, born before the thirtyseventh week of gestation, can be born with underdeveloped organ systems and other health problems that impact their ability to survive on their own outside of the womb.

Preterm birth and low birth weight are leading causes of infant death, childhood disability, and developmental delays. ${ }^{2}$ Among the smallest survivors (those born at less than twenty-six weeks gestation), 57 percent have a mild or moderate disability, and 23 percent have a severe disability. ${ }^{3}$ To support preterm and other medically fragile infants, many hospitals have neonatal intensive care units (NICUs) specializing in the care of these at-risk infants.

Traditional NICUs were set up as nursery wards where preterm babies in isolettes were kept together in one big room,

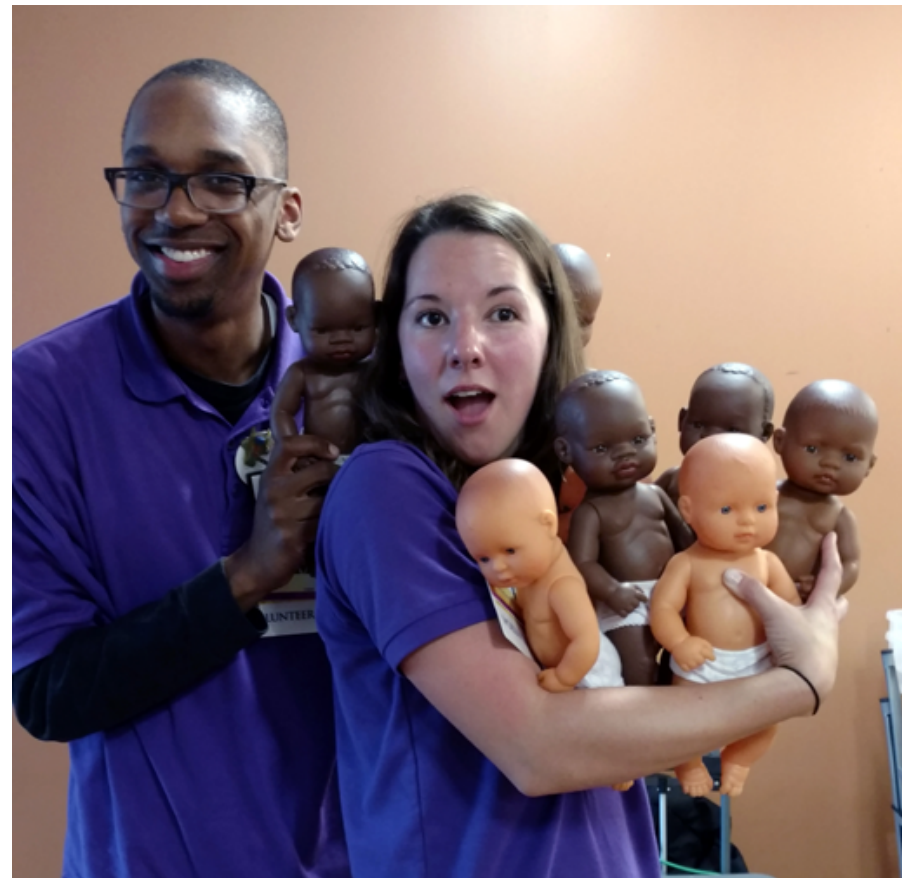

Parents and their "babies" learn how to share books through the Mother Goose on the Loose program, now utilized in some NICUs.

allowing easy access to the babies by a wide array of medical staff. As the medical field and research on preterm infants have evolved, so have NICUs. One significant change has been the trend toward becoming more family friendly. Cuddling and skin-to-skin contact are now recognized as beneficial for all but the frailest infants. And most recently, NICUs are being reconfigured from the ward setting to individual family rooms. Families are encouraged to stay together, and it has become much easier for parents to spend as much time as possible with their babies.

While these single-family rooms yield many benefits, an unexpected negative outcome is demonstrated in the MRI scans showing decreased brain development in infants in individual rooms versus wards, as well as in lower language assessments

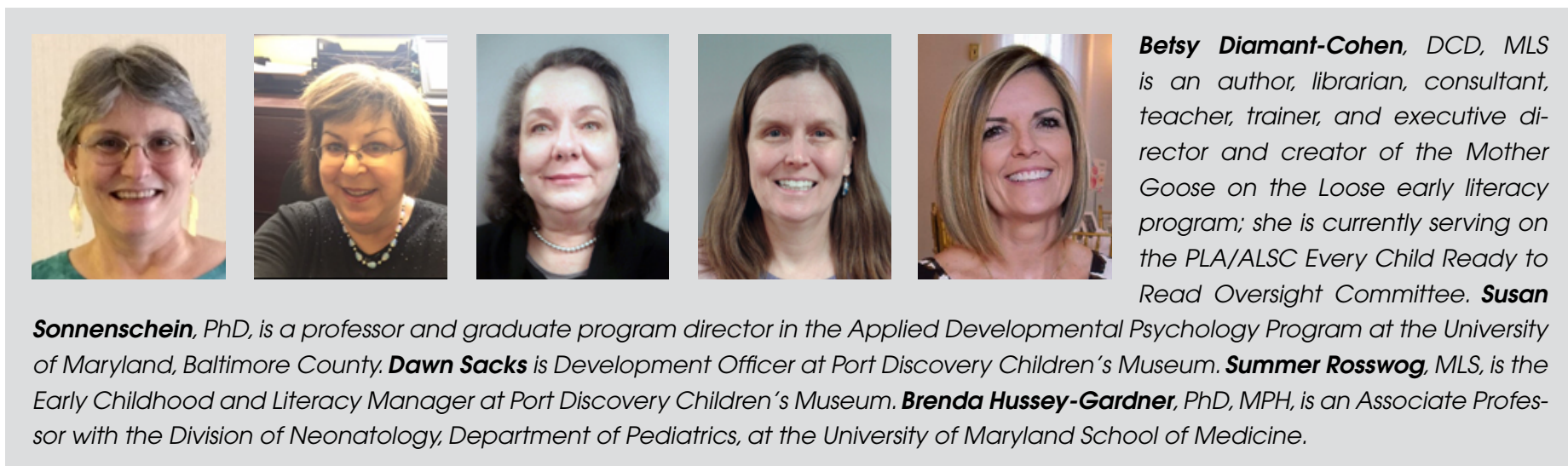


at two years of age. ${ }^{4}$ It has been suggested that these negative effects are the result of infants receiving less stimulation in NICU private rooms than in NICU wards. ${ }^{5}$ Additionally, although research shows that early contact between parents and babies is crucial to development, many NICU parents do not know how to optimally interact with their infants. This is especially true when health issues and medical equipment require physical separation and/or limited physical contact, which can become psychological barriers to bonding. ${ }^{6}$

Clearly, there is a need to help parents of infants in NICUs learn to interact appropriately with their young children.

\section{Never Too Soon for Early Literacy}

Infants and toddlers immersed in a rich environment of playful early literacy activities show significant gains in brain development and language acquisition, both of which correlate highly with greater reading and mathematics achievement, increased behavioral self-regulation, and fewer externalizing and internalizing problem behaviors at kindergarten entry. ${ }^{7}$ These large and significant effects have been documented as early as twenty-four months, and it is increasingly apparent that there are great benefits to providing a language-rich environment as early as possible. ${ }^{8}$

In 2015, Dr. Betsy Diamant-Cohen attended a water aerobics class led by a young woman who performed exercises that ignored the beat of the background music. A fellow exerciser pointed out that older water aerobics teachers seemed to have no problem moving to the beat, whereas the younger ones tended to use music merely as a background and were either unwilling or unable to coordinate their movements with the tempo and beat of the music. The woman remarked, "I think it's because their mothers didn't recite nursery rhymes with them.”

She continued, "I've been thinking about premature babies needing to hear their parents' voices and lamenting the fact that parents today don't know nursery rhymes. Wouldn't it be wonderful if we could teach these young parents some nursery rhymes so they would have something to sing and recite to their babies while visiting them in the NICU?" This woman had no idea that Cohen was a children's librarian or that she had developed the Mother Goose on the Loose early literacy program, but her comment sparked a lively discussion.

Knowing that early literacy begins at birth; that it is never too early to talk, sing, or read to a baby; and already believing in the power of nursery rhyme activities as a positive force for healthy child development, parent/child bonding, and good parenting skills, Cohen began researching the use of music and rhymes with premature babies. She found that studies indicated music in NICUs positively impacted infant health, feeding, and behavior. Health-related benefits included fewer episodes of oxygen desaturation, ${ }^{9}$ better cardiac and respiratory functioning, ${ }^{10}$ improved vital signs, ${ }^{11}$ and earlier discharge from the NICU. ${ }^{12}$ Feeding benefits included improved sucking patterns, better feeding behaviors, ${ }^{13}$ and higher breastfeeding rates at the time of discharge and sixty days later. ${ }^{14}$ Behavioral benefits included improved sleep, decreased crying, ${ }^{15}$ and less stress. ${ }^{16}$

In addition to being beneficial for preterm infants, music also benefited their parents. In one study, sharing musical activities with their infants resulted in parents feeling more involved in their infant's well-being. ${ }^{17}$ In another study, mothers who engaged in music and movement programs with their infants reported an increased quality of attachment with their child over time. $^{18}$

After reading all of this, Cohen was convinced that a musicand rhyme-based early language program for parents of premature babies was needed. She shared this developing interest with colleagues at Port Discovery Children's Museum, who urged her to write a proposal to create a program. And so the Mother Goose on the Loose: Goslings program was hatched.

\section{Serendipity Strikes}

Soon after the program proposal was developed, a representative of a community funder had a conversation with a staff member of the University of Maryland Children's Hospital, which had recently reconfigured to a NICU with individual family rooms. Hearing about the recent research on developmental delays tied to individual rooms, the foundation representative remembered Port Discovery and their exceptional early childhood programs. In fact, his foundation was already supporting these programs. Could he bring these diverse organizations together? He could and did.

The program partners of the original Goslings program included Dr. Betsy Diamant-Cohen (Mother Goose on the Loose), Summer Rosswog (Port Discovery Children's Museum), Dr. Brenda Hussey-Gardner (University of Maryland School of Medicine and University of Maryland Children's Hospital), and Dr. Susan Sonnenschein (University of Maryland, Baltimore County, Department of Psychology). These partners represented practitioners in the pediatric, research, and early childhood development fields. Bringing their unique skills to bear, the partners worked together to create, deliver, and evaluate a unique pilot program to enhance infant stimulation in the NICU and, eventually, at home.

All partners were involved in the development of the Goslings program script or in its evaluation. Traditional songs and nursery rhymes were modified in two ways. First, they were revised to address medical needs and concerns of small babies. Second, the songs and rhymes were then adapted to enhance parent-child bonding by having them use the word love. For instance, instead of "If you're happy and you know it, clap your hands," parents were encouraged to sing, "Since I love you very much, I'll make a heart."

These songs gave parents positive words to help them create nurturing environments for their children and strengthened 
their skills for future relationships with their babies. Informal developmental tips to accompany the activities were designed to provide cognitive and emotional support to parents at a most difficult time.

The final script included nursery rhymes, songs, descriptions of the signals babies give, developmental tips, and suggested responses by parents with the intent of fostering early language and literacy skills, enhancing positive parent-infant interactions, and strengthening attachment.

\section{Goslings Is Born}

Through the process of sharing, obtaining feedback, and modifying the program, the final Goslings program was brought to the NICU in 2016. We developed a kit with carefully selected items to best meet the needs of both premature and medically fragile full-term infants. It included finger puppets, colored scarves, musical instruments for little hands, an indestructible wordless book, Dr. Brenda Hussey-Gardner's Understanding My Signals book, ${ }^{19}$ a booklet of all the songs and rhymes used in the session, and a pass for a family visit to Port Discovery Children's Museum.

Since NICU infants are too medically fragile to leave their rooms and participate in Goslings, dolls of different races and cultures were purchased for use during the program. Isolettes were simulated by attaching plastic bins to metal stools. A magnetic board was purchased for the facilitator; on it, each song was given a visual representation to show what was coming next.

It was-and is-amazing to see how enthusiastically parents participate during a Goslings program. At first, they seem to feel a bit silly when asked to have a conversation with a finger puppet or to read a book to their "infant." However, mothers and fathers quickly join in, and by the end of the program, almost everyone is singing and participating. Family members forget they are interacting with a doll and sometimes act as if the doll is their infant; the love that they transfer to this "infant" is clearly visible. At the end of each program, parents are given an unopened kit to take back to their room to use with their baby.

\section{What Goslings Parents Say}

Incidental feedback from parents is positive. One father enthusiastically described what he had learned the previous week and how he was using that information with his twinschanting, singing, and reading to one who was medically stable while quietly holding the other one who was not as stable. One couple recounted that before the Goslings program they would wake their infant up to play with her whenever they visited. But after Goslings, they knew that sleep was the best thing for her, and they waited for her to wake up naturally before playing with her. Parents seemed to greatly appreciate

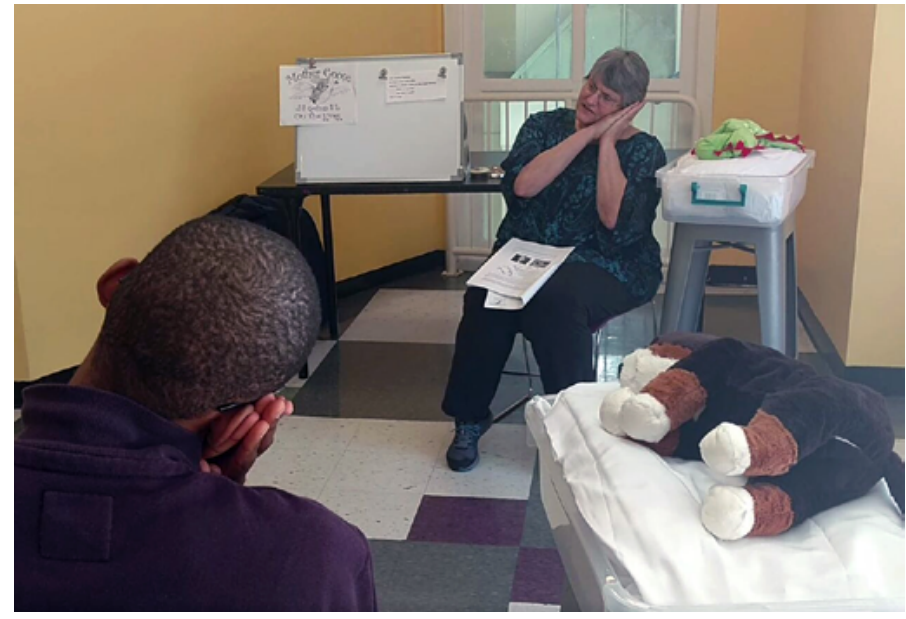

Training the Port Discovery staff for the first Goslings program

getting information about their infants' signals with the suggestions on how to respond appropriately. They enjoyed having activities to use with their children.

The father and mother of twins who had been released from the hospital after a lengthy stay said,

These two guys were born at twenty-seven weeks. . . We had a pretty lengthy stay [in the NICU]. We were there every day, but we weren't really sure how to interact with them in that environment. We attended one of the very first Mother Goose on the Loose: Goslings classes, and it was extremely helpful for us. It taught us to read their signs to see what kind of activities would be good for them that day. It gave us a book of songs that we could sing to them and showed us how to read books that rhyme and to kind of turn them into songs. We still sing the same songs to them today. We use the toys, like the scarves and the rattles. And it also taught us how to incorporate new things as they progressed from the isolette to the crib and eventually to home. We would highly recommend this program for all the other NICU parents, and especially those first-time parents like us.

\section{Formal Evaluation}

During waves one and two of Goslings, researchers in the Department of Psychology at the University of Maryland, Baltimore County, administered pre- and post-surveys to parents attending Goslings sessions. The primary questions of interest focused on whether the parents thought the program increased their knowledge of how to interact with their infants. It asked how often they talked, sang, shared books, and recited nursery rhymes with their children and how often they now expected to do so after the one-hour Goslings program.

In the second wave, researchers also conducted interviews with parents regarding actual implementation of the material used during Goslings. Within a week or two of attending the program, parents were asked how often they actually used these early literacy behaviors with their children. This was then compared to their intake survey. 
Based on the responses of parents during both waves of the program, Goslings was highly successful. All parents who completed the program said they would recommend it to other parents of infants in an NICU and would recommend that the program be implemented again. Almost all the parents thought they would significantly increase their linguistic interactions with their infants after completing the program, which they also thought had increased their knowledge of how and when to interact with their infants to stimulate their language development; for example, one parent said, "I have new ideas on ways to help my child grow and learn other than just holding them."

All the parents reported modifying their behavior based on attending Goslings. A noteworthy finding was that parents reported learning how to read or interpret their infants' signals, thus promoting more appropriate interactions. For example, they learned when the infant was telling them that he or she was overstimulated and not ready for further interaction.

Being sensitive and appropriately responsive to one's infant's signals sets the stage for fostering emotional bonding between the parent and the infant. Parents reported interacting in a developmentally appropriate manner with their infants; parents of more developmentally immature or fragile infants interacted less than parents of more mature infants.

Some parents already knew some or much of what the program taught; however, these parents reported liking that experts affirmed their knowledge. They also often reported learning to use their prior knowledge in a more developmentally appropriate manner for their infants. For example, they learned to speak more softly to their infants. Other parents learned that it was appropriate to speak and interact even with very young and medically fragile infants, and some parents of course increased their knowledge of the range of appropriate linguistic interactions. And another benefit of the program, according to some parents, was being able to interact with other parents like them. One parent commented, "You get to meet other families that may be going through something with their baby, and you have a chance to talk about it."

\section{Goslings: Today and Tomorrow}

From the unique needs of babies and their families in the NICU, Mother Goose on the Loose: Goslings was born. The program, now in its second year, takes place inside the hospital NICU with the cooperation of medical personnel, families, and early childhood program facilitators. Mother Goose on the Loose: Goslings is designed to teach parents in specific, effective strategies that support infants' early development, promote parent-child bonding, help parents provide a nurturing environment in the NICU and at home, and optimize infant language, social, and emotional development.

The long-term goal is to improve the odds for NICU infants, who are at significant risk for adverse developmental outcomes, by teaching and encouraging parents to provide the earliest possible developmentally appropriate stimulation through talking, reading, singing and using rhymes. A related goal is to provide comfort and support to parents in the NICU by teaching them to use purposeful play in appropriate ways with their fragile infants. This promotes familial bonding and provides a sense of empowerment and engagement with their fragile infants. A longer-term goal is to build a foundation for parents to continue reading and singing to their children at home, and to encourage attendance at early literacy programs once the children are healthy enough to visit their public libraries or local children's museums.

According to Hussey-Gardner, approximately 70 to 75 percent of NICU babies at her hospital receive medical assistance. Studies have shown that children from lower income homes hear fewer words and are slower at language processing, language comprehension, and language production. ${ }^{20}$ They have lower levels of grammatical development ${ }^{21}$ and are behind norms for spontaneous speech. ${ }^{22}$ The plasticity of the brain and its ability to form connections is based on what occurs in the child's first years of life. We know that parents are children's first and best teachers, young children develop in the environment of relationships, and the brain synapses upon which all future learning connects are formed in the earliest years of life. Therefore, another valuable future research question arising from Goslings might be, Does teaching NICU parents how to share books, rhymes, and songs with their infants in the earliest years of life help to instill habits for fostering healthy social, emotional, and intellectual development?23 If so, Goslings could be especially beneficial for low-income participants.

As previously noted, Goslings shows great promise. In the coming year, evaluation and research is being planned to assess the impact not only on parent intentions but also on parent behaviors and, potentially, infant developmental outcomes. If the data demonstrate the hoped-for outcomes, Goslings has the potential to influence parent and child support programs in hospitals across the country. There is also potential to modify the program to support very young children with special needs and their parents in nonmedical settings, such as in clinics and in Early Head Start programs.

As we continue to conduct research on the effectiveness of the program, the partners are exploring opportunities to share the knowledge gained by developing tools and training to extend the impact of Goslings. This is being done slowly and cautiously because because environmental stimuli and interactions that are inappropriate or not carefully monitored can cause damage. ${ }^{24}$

Through literacy programs, libraries and children's museums want to help children be the best they can be. As these informal learning centers strive to help underserved families, the Goslings program can help them reach the youngest children, giving them an early literacy foundation and much more. It teaches parents how to talk, sing, read, and play with their 
youngest children, even their premature or medically fragile full-term babies.

While NICU staff are appropriately focused on caring for the medical needs of their tiny patients, there is growing recognition of and appreciation for the role parents play in supporting infant development and in providing an environment rich in beneficial stimulation. Libraries and children's museums may have a significant opportunity to provide such programs.

We'd love to see Goslings expand beyond the University of Maryland Children's Hospital-and beyond Baltimore-to reach as many parents and infants as possible. Offering Goslings programs would be outreach at its finest, improving the lives of parents and our youngest children from all racial, cultural, and economic backgrounds. \&

Funding for development, implementation and research of the Mother Goose on the Loose: Goslings program was provided by The PNC Foundation Grow Up Great Program.

\section{References}

1. March of Dimes, "Peristats," accessed November 12, 2017, www.marchofdimes.org/Peristats.

2. Neil Marlow, Dieter Wolke, Melanie Bracewell, Muthanna Samara, "Neurologic and Developmental Disability at Six Years of Age After Extremely Preterm Birth," New England Journal of Medicine 352, no. 1 (2005): 9-19.

3. Ida Sue Baron and Celiane Rey-Casserly, "Extremely Preterm Birth Outcome: A Review of Four Decades of Cognitive Research," Neuropsychology Review 20, no. 4 (2010): 430-52.

4. Roberta G. Pineda, Jeff Neil, Donna Dierker, Christopher D. Smyser, Michael Wallendorf, Hiroyuki Kidokoro, Lauren C. Reynolds et al., "Alterations in Brain Structure and Neurodevelopmental Outcome in Preterm Infants Hospitalized in Different Neonatal Intensive Care Unit Environments," Journal of Pediatrics 164, no. 1 (2014): 52-60.

5. Melinda Caskey, Bonnie Stephens, Richard Tucker, and Betty Vohr, "Importance of Parent Talk on the Development of Preterm Infant Vocalizations,” Pediatrics 128, no. 5 (2011): 910-16.

6. Zahra Abdeyazdan, Zahra Shahkolahi, Tayebeh Mehrabi, and Mahnoosh Hajiheidari, “A Family Support Intervention to Reduce Stress among Parents of Preterm Infants in Neonatal Intensive Care Unit," Iranian Journal of Nursing and Midwifery Research 19, no. 4 (2014): 349-53.

7. Erika Hoff, "How Social Contexts Support and Shape Language Development," Developmental Review 26, no. 1 (2006): 55-58.

8. Anne Fernald, Virginia A. Marchman, and Adriana Weisleder, "SES Differences in Language Processing Skill and Vocabulary Are Evident at 18 Months," Developmental Science 16, no. 2 (2013): 234-48.

9. Rosemary C. White-Traut, Michael N. Nelson, Jean M. Silvestri, Minu K. Patel, and Diedre Kilgallon, "Patterns of Physiologic and Behavioral Response of Intermediate Care Preterm Infants to Intervention," Pediatric Nursing 19, no. 6 (1993): 625-29.

10. Rosemary C. White-Traut, Michael N. Nelson, Jean M. Silvestri, Nancy Cunningham, and Minu K. Patel, "Responses of Preterm Infants to Unimodal and Multimodal Sensory Intervention," Pediatric Nursing 23, no. 2 (1997): 169-77.

11. Joanne Loewy, Kristen Stewart, Ann-Marie Dassler, Aimee Telsey, and Peter Homel, "The Effects of Music Therapy on Vital Signs, Feeding, and Sleep in Premature Infants," Pediatrics 131, no. 5 (2013): 902-18.

12. Jayne M. Standley, "The Effect of Music and Multimodal Stimulation on Responses of Premature Infants in Neonatal Intensive Care," Pediatric Nursing 24, no. 6 (1998): 532-38.

13. Loewy et al., "The Effects of Music Therapy."

14. Shmuel Arnon, "Music Therapy Intervention in the Neonatal Intensive Care Unit Environment," Jornal de Pediatria 87, no. 3 (2011): 183-85.

15. Kimberly A. Allen, "Music Therapy in the NICU: Is There Evidence to Support Integration for Procedural Support?," Advances in Neonatal Care 13, no. 5 (2013): 349-52.

16. Roberta A. Polverini-Rey, "Intrauterine Musical Learning: The Soothing Effect on Newborns of a Lullaby Learned Prenatally," PhD diss., California School of Professional Psychology, 1992.

17. Shannon O'Gorman, “The Infant's Mother: Facilitating an Experience of Infant-Directed Singing with the Mother in Mind," British Journal of Music Therapy 20, no. 1 (2006): 22-30.

18. Wendy Vlismas, Stephen Malloch, and Denis Burnham, "The Effects of Music and Movement on Mother-Infant Interactions," Early Child Development and Care 183, no. 11 (2013): 1669-88.

19. Brenda Hussey-Gardner, Understanding My Signals: Help for Parents of Premature Infants, 3rd ed. (Palo Alto, CA: Vort, 2008).

20. Susan Sonnenschein, Linda Baker, and Robert Serpell, "The Early Childhood Project: A 5-year Longitudinal Investigation of Children's Literacy Development in Sociocultural Contest," in Literacy Development and Enhancement Across Orthographies and Cultures, ed. Dorit Aram and Ofra Korat (New York: Springer US, 2010), 85-96.

21. Christine A. Dollaghan, Thomas F. Campbell, Jack L. Paradise, Heidi M. Feldman, Janine E. Janosky, Dayna N. Pitcairn, and Marcia Kurs-Lasky, "Maternal Education and Measures of Early Speech and Language," Journal of Speech, Language, and Hearing Research 42, no. 6 (1999): 1432-43.

22. Janellen Huttenlocher, Heidi Waterfall, Marina Vasilyeva, Jack Vevea, and Larry V. Hedges, "Sources of Variability in Children's Language Growth,” Cognitive Psychology 61, no. 4 (2010): 343-65.

23. Erika Hoff, "Interpreting the Early Language Trajectories of Children from Low SES and Language Minority Homes: Implications for Closing Achievement Gaps," Developmental Psychology 49, no. 1 (2013): 4014.

24. Jayne M. Standley, "Premature Infants: Perspectives on NICU-MT Practice,” Voices: A World Forum for Music Therapy 14, no. 2 (2014): 1504-1611. 